\title{
SimUlation OF ViRTUAL MACHINE TOOL DURING THE DEVELOPMENT PHASE
}

\author{
Zdenek Hajicek \\ University of West Bohemia, Faculty of Mechanical Engineering, Univerzitni 8, 30614 Pilsen, Czech Republic \\ University of West Bohemia, Univerzitni 8, 30614 Pilsen, Czech Republic
}

\begin{abstract}
This paper deals with the simulation of CNC machine tools. The main focus is to develop a methodology for building virtual CNC machine tool. Virtual machine tool uses main properties of real machine. The goal is to simulate the functionality of the machine in virtual phases. This method is intended for complex and very expensive machines like milling and boring machine tools with numerous accessories. The current trend is to sell machine tools and equipments with complete technology of machining. Customer requirement is the virtual case study of real technology process. The idea of virtual prototyping is realized if the behavior of the virtual machine tool is in compliance with real machine.
\end{abstract}

Keywords: Simulation, Machine Tools, CNC, Sinumerik 840D, CSE machine driver
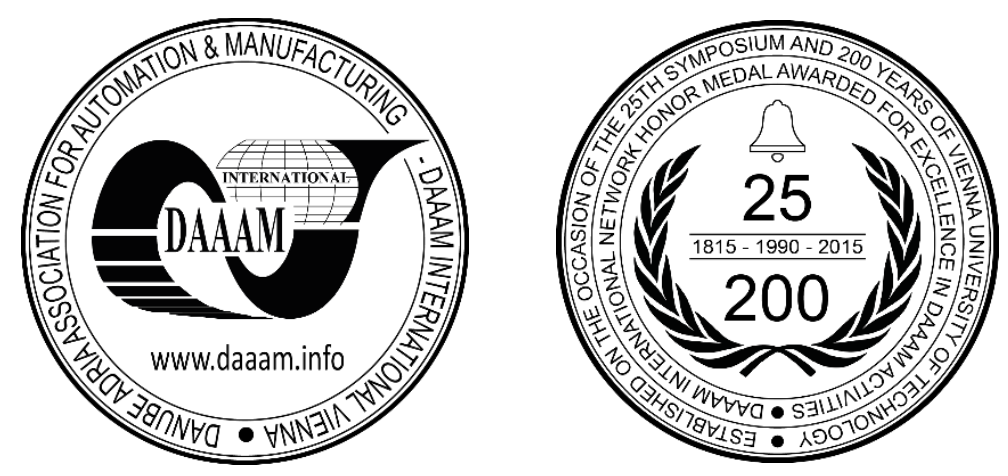

This Publication has to be referred as: Hajicek, Z[denek] (2016). Simulation of Virtual Machine Tool During the Development Phase, Proceedings of the 26th DAAAM International Symposium, pp.0948-0954, B. Katalinic (Ed.), Published by DAAAM International, ISBN 978-3-902734-07-5, ISSN 1726-9679, Vienna, Austria

DOI: $10.2507 / 26$ th.daaam.proceedings. 133 


\section{Introduction}

The current trend for Machine manufacture is to delivered Machine tools on a turnkey solution. This solution is based on typical customer part and technology. Thanks to this reality the company creates a case study. This case study is consists of the Machine tool, technical equipment and CNC technology in one complex 3D layout. The main purpose of the case study is guaranteed reliable information about the future behaviors of the Machine tool.

\subsection{Problem definition}

This thesis deals with optimization 3D layout of Horizontal milling machine and the possibility of using in engineering practice. The main problem is to simulate behaviours and functionality of CNC Machine tool in virtual phases. For the virtual verification of machines is used CSE simulation in PLM system Siemens NX 9. This CSE simulation uses a main properties axis and real kinematic of machine. The optimization has been created for a machine Skoda HCW 1000 and for special customer requirements.
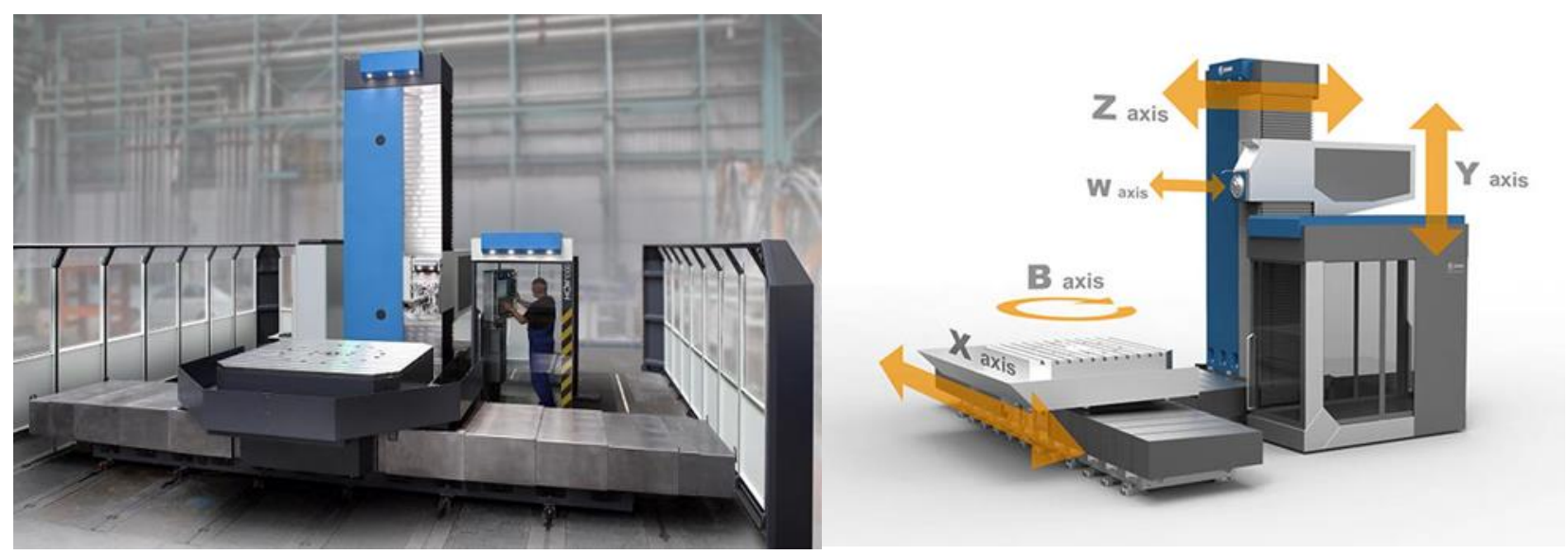

Fig. 1. Horizontal boring and milling machinetype of HCW 1000

\section{Literature review}

Modern machine tools are very complex mechatronical systems. The capability and efficiency of a machine tool are mainly determined by its kinematics, structural dynamics, computer numerical control system and the machining process [1],[16],[17]. The CNC system consists of a computer, power electronics components, such as motor amplifiers and electronic circuits, and servo actuators. The computer control unit receives ISO standard NC-programs which describe the tool path geometry, tool number, feed and spindle speed at each path segment [2], [3]. Simulation of the CNC system involves virtual modelling of the machine tool kinematics and feed drive dynamics, update of the workpiece geometry as the material is removed and motions of the drives and auxiliary units, such as tool and pallet changes. In short, the rigid body motion of the machine tool and the $\mathrm{CNC}$ functions must be predicted as the workpiece is produced in order to realize a Virtual CNC system [1].

Once the NC Program is generated in a CAD/CAM environment, the present Virtual CNC technology allows the geometric update of the workpiece as the tool cuts the material at each NC block. In addition, the solid model of the machine tool, its multi-axis kinematics and the location of fixtures can be displayed in the CAD environment [4], [5].

$\mathrm{NC}$-path simulation present technology allows the prediction of tool collision spots and correctness of the NC program by checking path errors and gauging on the workpiece surface graphically. Lauwers et al. [6], [7], [8], [9] take the CL file from the CAD system and simulate the machine motion by modelling the kinematics of the machine tool for collision detection and avoidance. In some commercial controllers machining simulation systems are integrated. During machining the simulation system runs a number of blocks ahead, and if there is a danger of a collision, the controller stops the machine immediately [1].

\subsection{CSE simulation in PLM system Siemens NX}

This simulation allow of many uses in engineering particle like testing a CNC code, prediction of collision during the machining and measure of machining times.Abbreviation of the word CSE is Common Simulation Engine and this simulation is driven by real NC code in Siemens, Heidenhain or Fanuc language. The main interpreter of CNC code is CSE Driver which controlsthe simulation like a real operation system. In Driver is programed machine kinematic with main setting of axis. For each axis is set Hard and Soft limit, Maximal speed, Maximal acceleration, Maximal deceleration, Fine precision, Coarse precision, Jerk, Jump Ability and KV factor. Next part of CSE simulation is Postprocessor. This Postprocessor translates CL data to CNC code automatically before simulation. 


\section{Current process}

\subsection{Requirements and solutions}

Main focus of this study is to develop virtual Horizontal milling machine for machining a block of headstock for Turning machine series SR1000. The machine must have a minimal 120 pieces of tools with automatic tool change. This machine can work in continual cycle of production. Because of these requirements is an emphasis on very quick automatic tool change.
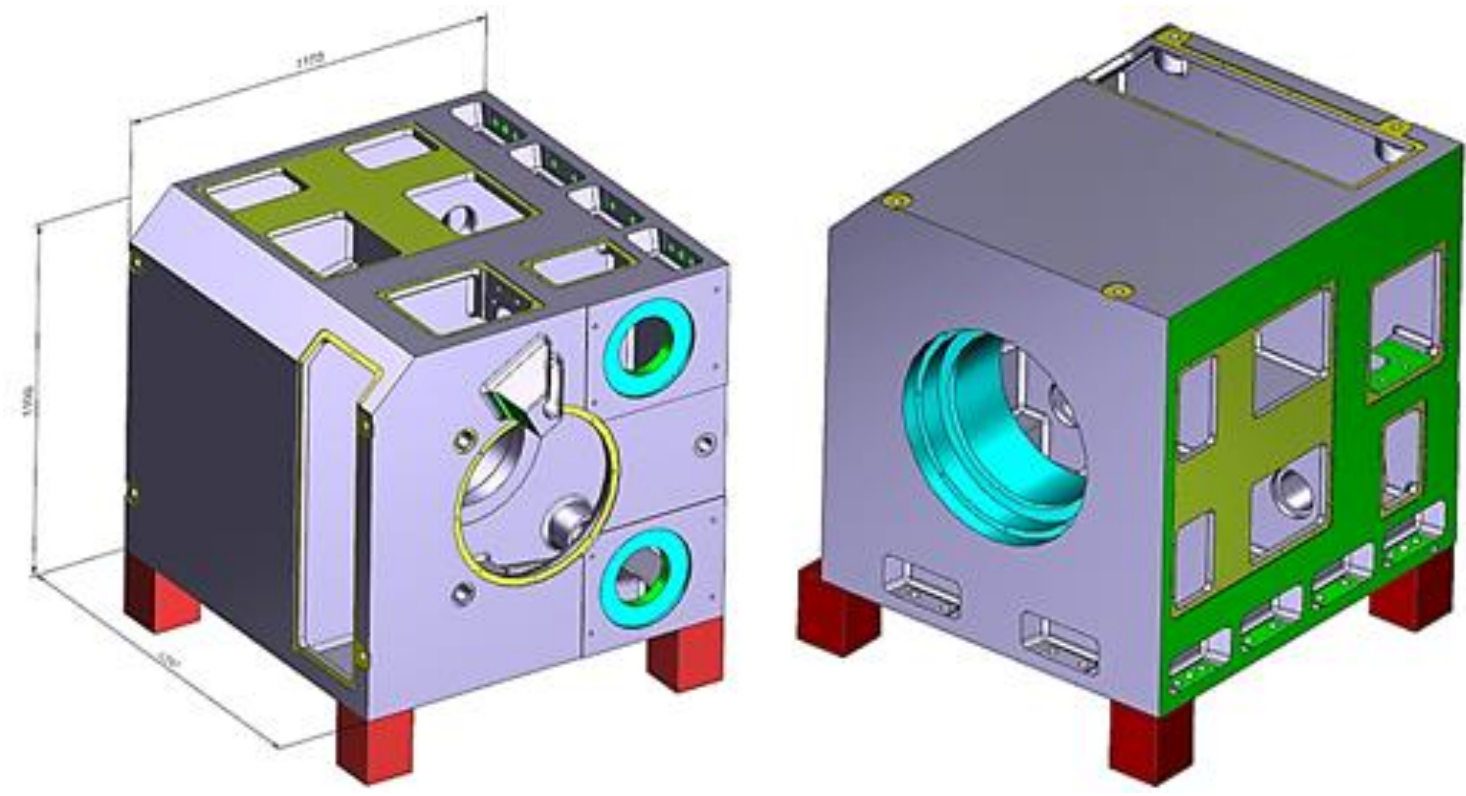

Fig. 2. Typical machining part for headstock SR1000

$\mathrm{T} \quad$ he main method uses the CSE simulation for prediction time to tool changing. Virtual machine is consists of 3D layout with three different concept of Automatic Tool Change (ATC) mechanism. The Horizontal machine has the same CSE kinematic chain but ATC mechanism uses three different. Each mechanism has dissimilar axis setup with main behaviours.
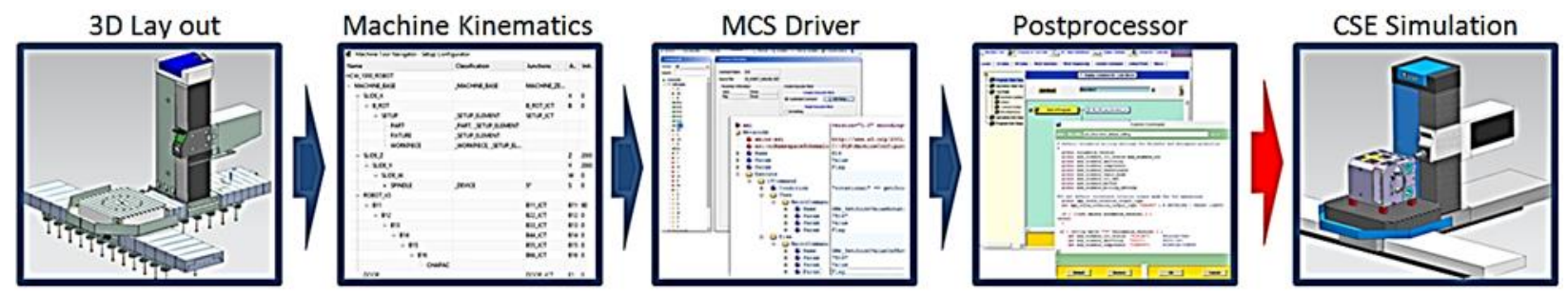

Fig. 3. Structure of CSE simulator

If during the simulation of machining process is called command for tool changing the CSE simulation move with ATC mechanism to the required position for the tool changing. Time for this move is relevant with five percent probability. Thanks to this method it was created three virtual CSE simulators one for original solution and two new optimizations.

\subsection{The first variant before optimization}

The Horizontal milling and boring machine type HCW 1000 before optimization uses simple automatic tool change for maximal 63 pieces of tools. Tools are situated in special tool chain with tool pockets. With using typical maximal tool with length $475 \mathrm{~mm}$ and dimension $300 \mathrm{~mm}$ the number of tools is decreased. Time of motion for tool change mechanism is simulated to 30 seconds and this time is inconvenient. This non-cutting move must be shorter. The main advantage of this solution is very cheap price. This price can be 14800 Euro for this base automatic tool change. Solution for continual cycle of machining is designed with full covered area like compact modern CNC milling centre. 


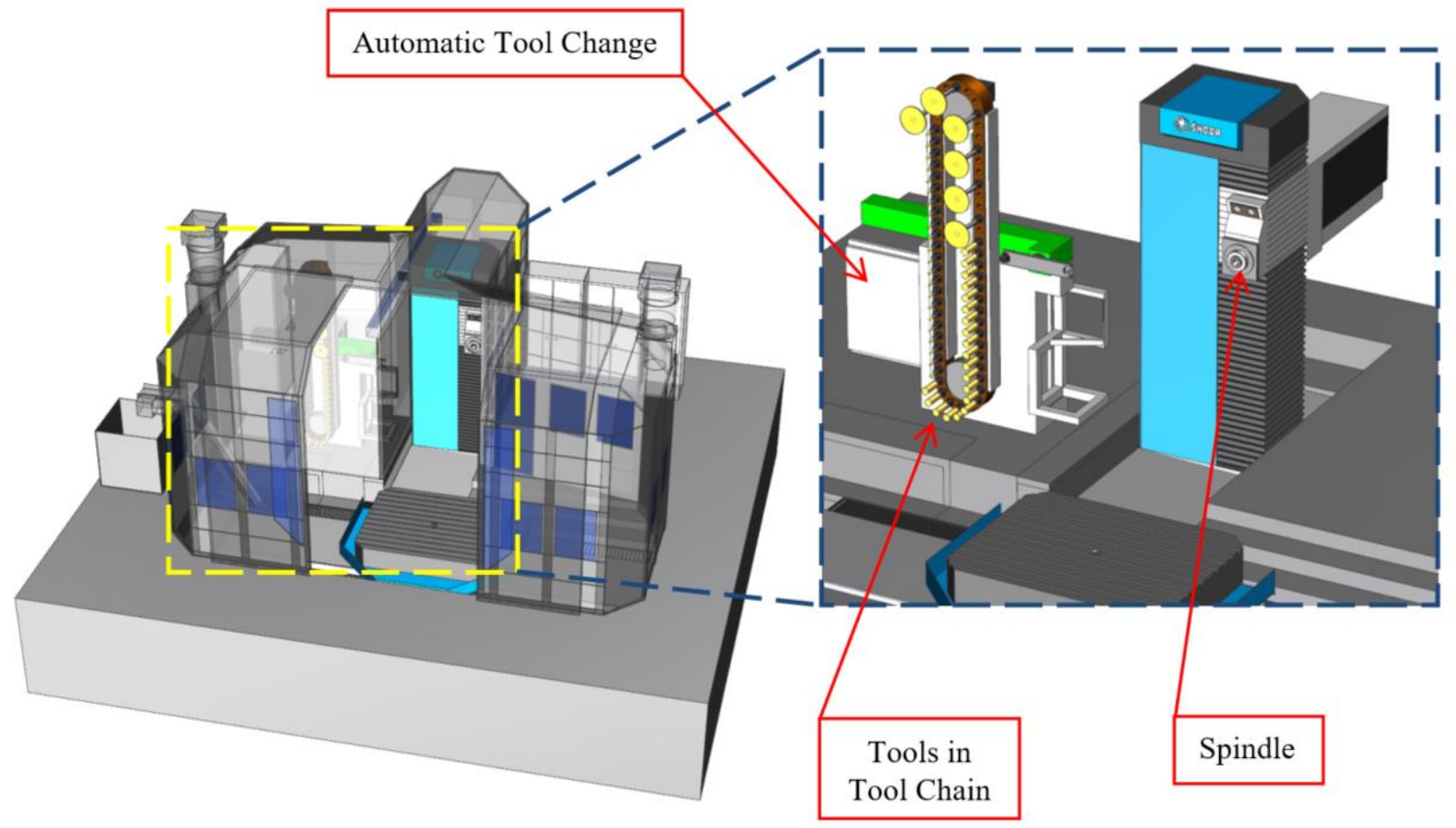

Fig. 4. CSE simulator Horizontal milling machine with detail to base automatic tool change

\section{The main research and optimization}

For optimization and design new layout has been prepared two different solutions. The first solution is focused on base customer requirements and the second is focused on continual cycle of production with high productivity. For design the Tool Housing has been selected three representative tools depending to size.

\begin{tabular}{lcc}
\hline Name of tool & Length $(\mathrm{mm})$ & Diameter $(\mathrm{mm})$ \\
\hline Basle tool & 200 & 22 \\
Middle tool & 320 & 80 \\
Large tool & 475 & 300 \\
\hline
\end{tabular}

Table 1. The main representative of tools.

The main operating mechanism is industrial robot for both solutions. This industrial robot uses special tool gripper with two pockets for tools. This gripper can grasp two tools together due to the rapid tool change in to the spindle. The robot with gripper arrive to changing position before spindle, the first jaw mechanism remove tool form spindle, rotate ninety degrees and the second jaw mechanism insert new tool in to the spindle. This movement takes maximal five seconds. The first solution uses industrial robot KUKA series KR 30 and the second solution uses robot KR 90.
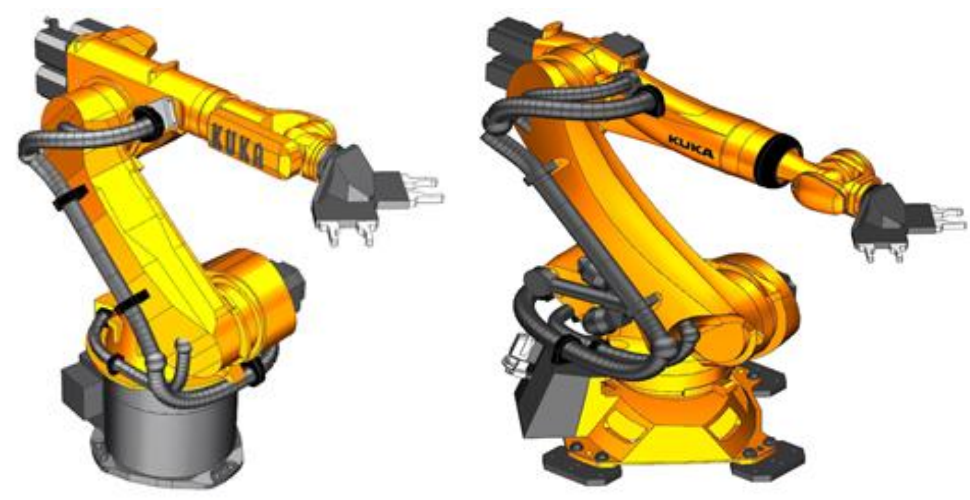

Fig. 5. Industrial Robots KR 30 and KR 90 


\subsection{The first optimization with robot KR 30 and circle arena}

First optimization uses circle Tool Housing with four shelfs for tools. Two shelfs are used for Middle representative tools, third for Base representative tools and fourth for Large representative tools. Total number of tools in Tool Housing are maximal 137 pieces. Time of motion for tool change mechanism is simulated to eight seconds and this time is satisfactory. Price of this solution is higher than original solution without optimization. The estimated price of first optimization is 129500 Euro. This solution also presupposes full covered area like compact modern CNC milling centre.

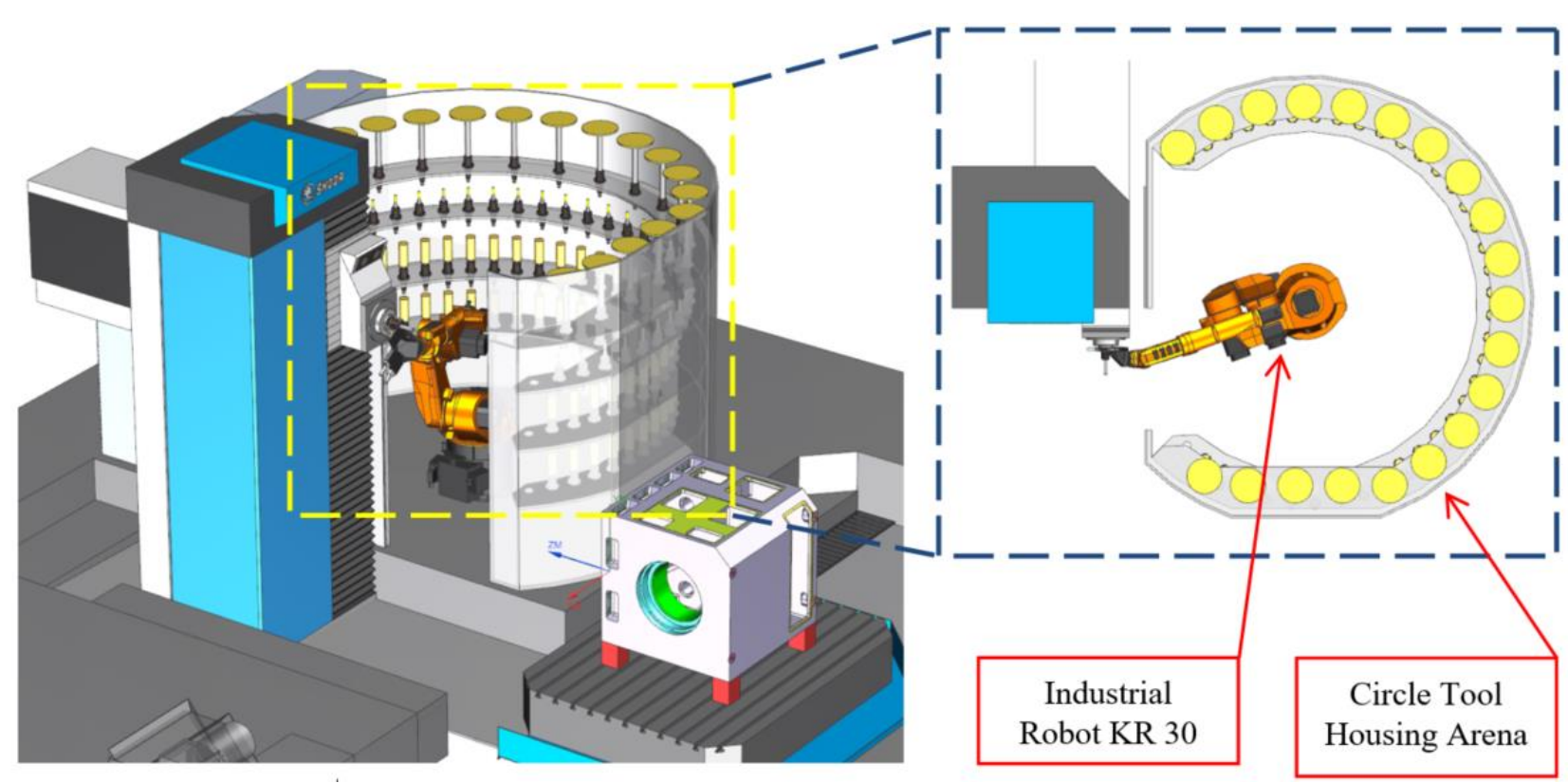

Fig. 6. CSE simulation of HCW 1000 andRobotic Tool Change with Circle Arena

\subsection{The second optimization with robot KR 90 and Carousel Arena}

The second concept of the 3D layout is designed for using high number of tools. This solution uses up to 432 tools. The machine tool is designed for a continual cycle of the production. It consists of a pallet system for workpiece changing and the automatic tool change with an industrial robot KR 90. This system consists of three pallets. Every time only one pallet can be in work place. Other two pallets are used for clamping workpiece because this part must be machining for all faces. The first pallet is used for a main clamping workpiece position and the second is used for the reposition for bottom milling. This technology uses two CNC programs which are changed by the current workpiece position.

Thanks to the continual production the customer requires that all tools must be delivered twice. Before inserting of the tool to the spindle or to the Carousel Tool Housing Pocket, the robot checks the tool by the laser or the optical measuring system. If the tool shows signs of damage the robot forwards the tool to the machine operator to repair and to change it.

To ensure a large number of tools, Tool Housing designed by three carousels with three rotating shelves. This case study uses 144 Base tools, 144 Middle and 45 Large tools. Altogether there are 333 mixed tools in one Tool Housing. Time of motion for tool change mechanism is simulated to nine seconds and this time is also sufficient. This solution is the most expensive of these three. The price of the second optimization is 185000 Euro. 


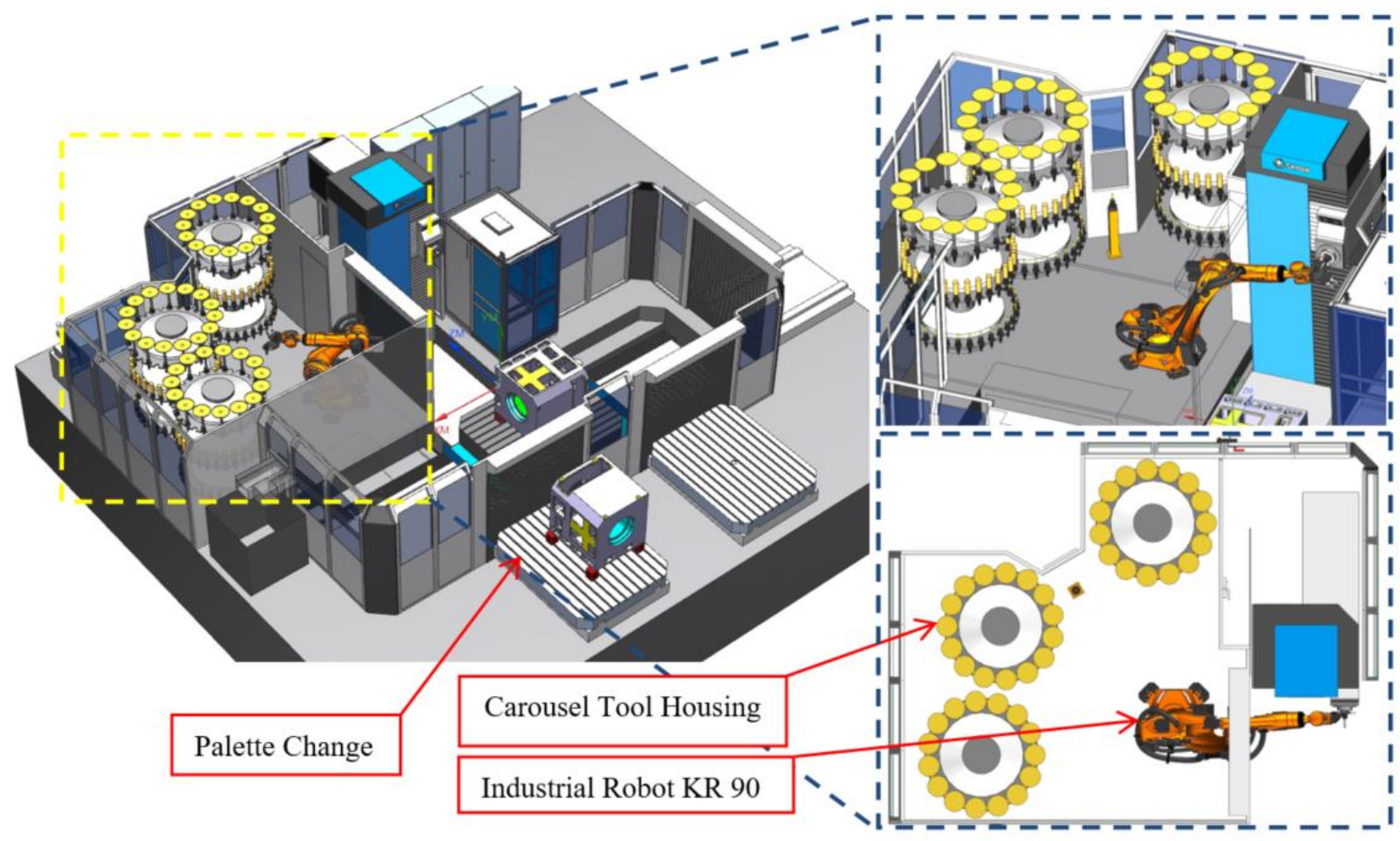

Fig. 7. CSE simulation of HCW 1000 andRobotic Tool Change with Carousel Arena

\section{Conclusion and results}

From entry requirements we need optimized old solution. New requirements for Machine Tool are machining the typical part headstock SR1000, machining in continual cycle of production and minimal number of tools in automatic tool change are 120 pieces.

It has been programmed three CSE simulation for current machine with classic automatic tool change. First optimization has been designed simulation with industrial robot KR 30 and it uses circle Tool Housing Arena. The second optimization has been designed simulation with robot KR 90 and with carousel Tool Change Housing.

Customer can choose from two different solutions. First solution (optimization 4.1.) has advantages in lower price and very short time of tool changing. But main disadvantage is low number of tools in Tool Housing. For continual cycle of machining is much better highest number of tools in Tool Housing for automatic tool change. The second solution (optimization 4.2.) has main advantage in very high number of tools in Carousel Tool Change Housing. But main disadvantage is highest price than first optimization with robot KR 70.

\begin{tabular}{lccc}
\hline Version of case study & $\begin{array}{c}\text { Time of motion for } \\
\text { tool change } \\
\text { mechanism (s) }\end{array}$ & $\begin{array}{c}\text { Number of tools in Tool } \\
\text { changer }\end{array}$ & $\begin{array}{c}\text { Price of Tool changer } \\
\text { (Euro })\end{array}$ \\
\hline Without optimization & 30 & 63 & 14800 \\
Optimization 1 & 8 & 137 & 129500 \\
Optimization 2 & 9 & 432 & 185000 \\
\hline
\end{tabular}

Table 2. The main representative of tools.

\section{Further research}

The CSE simulation is very suitable for many kinds of machine tools with lot of machinery equipments. The Further research will be focused on construction and verification this two solutions with industrial robot in technical practice. The next research will include detailed simulation of motion and positioning Robotic Arm in Tool Housing Arena with Tool Management Sinumerik 840D.

\section{Acknowledgements}

The paper was supported by “ University of West Bohemia, Department of Machine Design, SGS 2015” 


\section{References:}

[1] Y. Altintas, C. Brecher, M. Weck, S. Witt, 2005, Virtual Machine Tool, CIRP Annals, 50/2: 115-138.,

[2] Pritschow, G., Altintas, Y., Javone, F., Koren, Y., Mitsuishi, M., Takata, S., Van Brussel, H., Weck, M., K. Yamazaki, 2001, Open Controller Architecture-past, present and future, Annals of the CIRP, 50/2: 446-463.

[3] Pritschow, G., Berkemer, J., Bürger, T., Croon, N., Korajda, B., Röck, S., 2003, Die simulierteWerkzeugmaschine, TagungsbandFertigungstechnischesKolloquium Stuttgart, 219-246

[4] Yeung, C.Ho, Altintas, Y., Erkorkmaz, K., 2004, Virtual CNC System, Part I: Architecture and Auto tuning of CNC Systems, Trans. ASME, J. Machine Tool Manuf. Eng.Manufacturing Science and Engineering.

[5] Yeung, C.Ho, Erkorkmaz, K., Altintas, Y., 2004, Virtual CNC System, Part II: Virtual Part Machining and auto correction of contouring errors, Trans. ASME, J. Manufacturing Science and Engineering.

[6] Kruth, J.P., Lauwers, B., Klewais, P., Dejonghe, P., 1999, "NC-postprocessing and NC-simulation for five-axis milling operations with automatic collision avoidance", International Journal for Manufacturing Science and Technology, 1(1), 1999, 12-18.

[7] Lauwers, B., Kruth, J.P., Dejonghe, P., Vreys, R., 2000, Efficient NC-programming of multi-axes milling machines through the integration of tool path generation and NC-simulation, Annals of the CIRP, 49/1/2000: 367-370.

[8] Lauwers, B., Van der Poorten, E., De Baerdemaeker, H., 2003, CAD/CAM based generation of collision free robot programs through the integration of a virtual machining environment, European Journal of Mechanical and Environmental Engineering,47/4: 215-220.

[9] Lauwers, B., Dejonghe, P., Kruth, J.P., 2003, Optimal and collision free tool posture in five-axis machining through the tight integration of tool path generation and machine simulation, Computer- Aided Design, 35 (5): $421-432$.

[10] Milling with Sinumerik: Manual 5-axis machining. Deutschland: Siemens AG, 2009.

[11] Siemens product lifecycle management software, NX 8.5 Help Library,USA: 2012.

[12] Post building techniques: Student Guide - Post Builder 3.5. United States of America: UGS Corporation, 2006.

[13] Milling with sinumerik: Mold making with 3 to 5-axis simultaneous milling. Deutschland: Siemens AG, 2011.

[14] Sinumerik 840D: Advanced Programming Guide. Deutschland: Siemens AG, 2004.

[15] Ming, C. Leu A Joshi Akul. Department Of Mechanical and Aerospace Engineering. Nx5 for Engineering Design. U.S. state of Missouri: Missouri Uneversity of Scieneceand Technology, 2008.

[16] Mike Wilson, Implementation of Robots Systems, United Kingdom, 2014, ISBN: 978-0-12-404733-4.

[17] F. Koenigsberger, J. Tlusty, Machine Tool Structures, Elsevier, 2013, 148316053X, 9781483160535. 